\title{
What Place does the Real-Relationship have in the Process of Therapeutic Character Change?
}

\author{
Patrice Duquette, MD \\ Detroit Psychiatric Institute, Detroit, Michigan
}

Follow this and additional works at: https://jdc.jefferson.edu/jeffjpsychiatry

Part of the Psychiatry Commons

Let us know how access to this document benefits you

\section{Recommended Citation}

Duquette, MD, Patrice (1993) "What Place does the Real-Relationship have in the Process of Therapeutic Character Change?," Jefferson Journal of Psychiatry. Vol. 11 : Iss. 2 , Article 11.

DOI: https://doi.org/10.29046/JJP.011.2.008

Available at: https://jdc.jefferson.edu/jeffjpsychiatry/vol11/iss2/11

This Article is brought to you for free and open access by the Jefferson Digital Commons. The Jefferson Digital Commons is a service of Thomas Jefferson University's Center for Teaching and Learning (CTL). The Commons is a showcase for Jefferson books and journals, peer-reviewed scholarly publications, unique historical collections from the University archives, and teaching tools. The Jefferson Digital Commons allows researchers and interested readers anywhere in the world to learn about and keep up to date with Jefferson scholarship. This article has been accepted for inclusion in Jefferson Journal of Psychiatry by an authorized administrator of the Jefferson Digital Commons. For more information, please contact: JeffersonDigitalCommons@jefferson.edu. 


\title{
What Place Does the Real-Relationship Have in the Process of Therapeutic Character Change?
}

\author{
Patrice Duquette, M.D.
}

\begin{abstract}
The relationship between therapist and patient is an important tool in the process of helping a patient change. There are various elements that make up the total relationship between patient and therapist, each with its own power to exert for and against change. Transference can be one of the most relentless of these elements in maintaining the status quo for our patients. To help our patients make significant gains against this relentless pressure is most of our task in psychotherapy. The real-relationship has been considered in the literature since the early 1940's and is described by Greenson as "the realistic and genuine relationship" between patient and therapist (8). There has been an increasing amount of discussion about the real-relationship and its application as a resource in the psychotherapeutic process. This article considers several writers'current views on the issue and proposes points at which therapists may focus their care and attention to effect deeper, more lasting therapeutic changes.
\end{abstract}

What is necessary in an on-going psychotherapeutic relationship to enable people to make lasting changes in their characters and lives? Over the years that the methods of psychoanalysis and psychotherapy have developed, many different answers have been considered. How does one human being help others to alter the basic means by which they comprehend, experience, and interact with the world? A primary focus has come to rest on the relationship between the two people involved, the patient and the therapist. This relationship can be broken down into more elementary aspects such as transference, the working alliance and the realrelationship. In this paper I shall consider how thoughtful psychotherapeutic work with these factors can facilitate lasting changes in the patient's character.

Before considering how we may help a patient make changes, an important aspect of the process of change itself must be noted. We do not often reflect on how very difficult it is to alter one's pattern of experiencing and relating to the world. When we do consider what must happen if change is to occur, we realize the subtle yet powerful forces a patient must grapple with constantly. Richard Simons attended to this issue well in his Presidential Address to the American Psychoanalytic Society in 1988 (1). He stated we "need to give attention to the anxieties over a future not so

Patrice Duquette, M.D. recently finished her psychiatric residency at the Detroit Psychiatric Institute and is currently working at a community psychiatric hospital near Detroit. 
controlled by the past," as that future brings both "surprise and responsibility." $\mathrm{He}$ cautions that "the translation of insight into creative action and sustained behavioral change evokes as many anxieties and resistances as the initial achievement of insight itself (1)." If we bear this idea in mind we can realistically evaluate ways to facilitate change, keeping the patient's interests foremost.

One essential factor of the relationship, transference, is a universal phenomenon. It can impacts on our relationships in deleterious ways and it is these harmful effects which most psychotherapeutic or psychoanalytic processes intend to change. Yet what action to take, in regards to transference, creates controversy.

Hans Loewald restates Freud's original ideas on transference in his paper on the therapeutic action of psychoanalysis. He believes transference is given essentially two meanings by Freud, either the transfer of libido (defined as object cathexis), or the transfer of a relationship from the past onto a relationship of the future (2). He concludes that transference cannot be eliminated fully from any relationship. Rather, transference must be present at some level in any relationship, albeit at an unconscious level.

Representing transference in this way does not undermine the fact that at the end of a successful psychotherapy or analysis the distorting effect on the person's experience is alleviated. As Loewald continues to consider the same issue, "The 'resolution of the transference' at the termination of an analysis means resolution of the transference neurosis, and thereby of the transference distortions (2)." Thus we help the patient change his or her ingrained view of the world, which has requisite distortions due to the process under which such a view came into being. What will be resolved is the patient's use of unhealthy interaction or distortions of reality. It is unnecessary, therefore, to quantify what elements of actual transference may be left within a patient's unconscious mind because the changes the patient makes will be in his or her behavior, physiology, and manner of relating in the world. If the effect of transference, i.e. the distortion, is removed, it is immaterial to consider the actual transference trace that still may be present in the unconscious.

Other authors have considered the phenomenon of transference. Ralph Greenson clarified several elements of the therapist-patient relationship that assist the patient and therapist in reducing its potentially distorting force in a person's life. As Greenson describes transference, it

"is the experience of feelings, drives, attitudes, fantasies, and defenses towards a person which are inappropriate to that person and are a repetition, a displacement of reactions originating in early childhood. I emphasize for a reaction to be considered transference it must have two characteristics, it must be a repetition of the past and it must be inappropriate to the present (3)."

Greenson considers the distortions transference imposes on the processes of the conscious mind by his inclusion of attitudes and fantasies. This describes a perspective from which we can help the patient. The distortion created by transference can be broken down into two elements, either of which could be discovered and elimi- 
nated if one were to hold them against the standard of present day reality. Any amount of distortion should be discernible by a person, then, if he or she is able to clarify the reality of the relationship in which he or she is currently involved. Thus one could theoretically eliminate the distorting effects of the transference on the conscious mind, and take a major step on the long road to psychic health.

It is only with the help of others that one can engage in this process which requires confronting many aspects of oneself which are too painful and frightening to take issue with alone. A thoughtful and respectful therapist can help a person find the means to begin and continue this painful, frightening process. The primary means to this end in our work with patients is another factor of the relationship called the "working alliance." It is through this alliance that we join the patient in the psychotherapeutic process, and also apply force to release the hold that the transference distortions have on them.

The consideration of such issues between therapist and patient as the working alliance did not occur in the original developmental steps of psychoanalysis. Freud wrote on issues involving the relationship and surely had utilized various aspects of it in his work (4), but the analytic profession had largely considered the process a one-person field. A Viederman writes, "It was Sterba (1934) who, in using the word 'we', focused on the real transaction between the analyst and the healthy observing ego of the patient $(5,6)$."

Greenson elaborated on this idea with many case examples and discussion $(3,7)$. He believed that the alliance develops almost "imperceptibly." It is the glue that keeps the patient and the analyst together, while at the same time providing fuel with which the process gains energy. He stated he was most aware of it, and the need for it, when the process between him and his patient was not working well. Both the therapist and the patient contribute to the working alliance. The patient's contribution to the working alliance "depends upon two antithetical properties: his capacity to maintain contact with the reality of the analytic situation and also his willingness to risk regression into his fantasy world. It is the oscillation between these two positions that is essential for analytic work (3)." It is commonly described in terms of the patient's ego, that is, the patient's observing or rational ego aligns itself with the working ego of the therapist.

Greenson knew that the transference distortions could invade the working alliance if not scrupulously monitored. In a well-functioning and effective psychotherapy a therapist must be aware of such instances. According to Greenson's examples $(3,7)$, an alliance that seems either too good or too bad should be suspected of having interferences in it on either the therapist's or the patient's part or both. If on the patient's part, these interferences should be made apparent to the patient through interpretation. If on the therapist's part, he or she must work to clarify his or her interfering countertransference.

The therapist also makes a contribution to the alliance. Some important embellishments of this idea were made by Viederman who considers the therapist's "countenance," "affective presence," and "ease and responsiveness," important contributions to a solid working alliance. He also believes "the analyst's particular 
stance in relation to change encourages the patient to overcome inhibitions and to confront the world in a new way (8)." And certainly he or she must maintain "a consistent and unwavering pursuit of insight with any and all of the patient's material (8)," and help the patient do the same.

One important aspect of building a working alliance is the non-acting out contract. The essence of such a commitment is that the patient would not, on the basis of feelings, take action. Rather, the patient would agree to carefully weigh whether or not proposed actions make sense and only then consider proceeding. A patient who comes for help may not fully grasp the implications of this commitment. While helping the patient consider such a commitment consciously, important groundwork is laid in the relationship between patient and therapist. As the patient is an important contributor to the working alliance, the therapist facilitating such an alliance becoming more conscious and less "imperceptible" will bring the patient in as a more active partner in the relationship. The patient is helped to see that he or she may consciously choose which action to take, may verbalize any and all sense of his or her experience, and may take a position in regards to his or her sickness.

Within the working alliance, then, the therapist has a method to apply necessary force to the transference distortions. For example, the therapist can intervene to help the patient use his or her observing ego to consider any irrationality in his or her actions or perceptions. The process of these "interventions" is undertaken from a position of noting what is real in the situation, and what is a distortion of reality on the patient's part. The process of doing so is neither simple nor easy. It requires much hard work on the part of the therapist and on the part of the patient. The therapist must maintain discipline and integrity when observing and intervening with the patient. He or she must also help the patient give up the "known safety" of his or her illness for a reality that requires effort and has variability in it. Such work must be done with care and consistency on the therapist's part. Again, it is necessary to keep in mind that the process of change itself stimulates powerful anxiety.

Natan HarPaz has also commented on the intrinsic difficulties in the therapeutic work, especially at the beginning (9). It is then that the therapist and patient are immediately at odds in regards to their intentions. The patient wishes to feel good, or at least better, while the therapist's goal is to confront the patient's illness. Thus the relationship starts on shaky ground. Such a process the patient would surely retreat from unless he or she experiences some solid ground from which to begin the painful and difficult work. This solid ground is the real-relationship, the core of the working alliance.

Greenson considered the historical context of the real-relationship and begins with a discussion by Esther Menaker in 1942 (10,11). He notes appropriately that there "has been considerable disagreement and frequent lack of clarity." In several of his writings he considered various issues and provides a definition that can be considered as an elementary beginning to a complex subject. He defined the real-relationship as, "the realistic and genuine relationship between patient and analyst (7)." This therapeutic formulation allows us to proceed in our understanding of the real-relationship. 
Others have more recently expanded on what is meant by the real-relationship $(6,8,12,13)$. It is unique to these two people, the patient and the therapist. It results from the mutual respect they have for each other. It also holds honesty as essential. It relates to a commitment the two parties have to continuing the work even in the midst of strong feelings on the part of the patient. It allows for the presence of all feelings to any degree of intensity and makes room for their vocal, but not behavioral, expression. Therefore it requires a commitment to take action based on what makes sense to do in the reality of the present. These qualities are not evident to the patient originally but are operative based on the manner in which the therapist begins the treatment.

Basic to the development of a real-relationship is the therapist's "humanness." Patients cannot be expected to trust a therapist who is not genuine. If the therapist expresses him or her self, without revealing life history but rather with repeated respectful and authentic contact, the patient will gain an important sense of the therapist as a human being $(8,12)$. As the therapist allows his or her real self to enter into this relationship it can be used as a consistent referent for the patient. It can lessen anxiety for the patient that would otherwise be overwhelming. This essential element will help in the fight against the patient's illness. It will lend a real weight to the patient's belief that someone is with them who can and will, see, hear, and talk with them about the issues that seem so frightening in solitude. Such an experience will also help to better separate the reality of current experience from the transferential experience $(8,9,12)$.

A therapist's humanness is one of the most difficult issues to consider when attempting to develop theoretical concepts, as it is the most variable. Writers on the subject have considered such qualities as the therapist's patience, tolerance, empathy, and style in working his or her craft as some examples of how this "humanness" is relayed to the patient $(1,8,12,13)$. Milton Viederman has written several articles on the "real person" of the analyst. In his latest article he attempted to place it "center stage as an aspect of the therapeutic process that leads to change (8)." He includes several illuminating clinical vignettes that allow the reader to get some sense of his person, as well as the clinical issues of the patient and how his person impacted on the patient. He writes

"To pretend that these factors do not powerfully influence the interaction with patients is not only to ignore the obvious, but more important to ignore something positive that facilitates the analytic process. The patient's engagement will be a product of the experience with the analyst that goes beyond intellectual analysis of defense and other content (8)."

Thus Viederman is helping us begin to describe theoretically how inevitable and yet important it is that a therapist express his or her "humanness." This quality will come to the fore as a therapist works through his or her own difficulties in psychotherapy. A therapist's ability to be genuine is hampered by his or her own fears of intimacy that are expressed in various ways through contact, or lack thereof, with patients. Supervision and theoretical seminars are other necessary aspects to help a 
therapist fully develop clinical skills. Blending the theoretical issues and personal understanding of such issues effectively is the most delicate aspect of the therapeutic work.

Thus the working alliance and specifically the real-relationship provide the framework and the holding power within which change is possible. As Reuven Bar-Levav states,

"Only within the real-relationship of properly conducted therapy is there enough room for a parallel therapeutic relationship in which the patient is free to express every thought and feeling and which requires no mutuality except for the payment of a fee. No other lasting relationship allows such complete freedom [...] (12)."

It is within the experience of the real-relationship that movement can be made to free the patient from the damaging effects of transference. Exactly how the work will be done must differ somewhat from patient to patient due to the real-relationship with all its implications. As Viederman notes, "Each analytic relationship has qualities that reflect the uniqueness of the relationship and that make it different from any other analytic relationship (8)." There are guidelines, however, that lend themselves to technique. It is within these guidelines, and with experience working with other therapists who can help the individual develop, that practitioners can find their own individual style of employing technique.

As the patient progresses in the work, measures will have to be taken to hold sway against the transference distortions. As the relationship develops the patient experiences deep infantile yearnings and affects that had previously been defended against. If a patient can be helped to observe himself and reality, while in the midst of such intense experiences, essentially new choices can be made. Thus the developmental process that was halted will be begun again, under the guidance and assistance of the therapist. The patient will be a more active participant during this process than before when the developmental process was unfolding in the first years of life. This is when a therapist can help a patient make changes in his or her character structure. But it is important to note that the therapist must be a very important presence in a patient's life to stimulate this new developmental process. It is within their coexistence in the real-relationship, and because of it, that this developmental work can be done.

As this developmental process unfolds, the therapist will become available as a "new object" to the patient. As Loewald writes, "The new discovery of oneself and of objects, is made possible by the encounter with a 'new object' which has to possess certain qualifications to promote the process (1)." The patient's renewed development will have the opportunity to proceed in a different direction, a direction that should be pointed toward a healthier character structure. Loewald postulates further that the therapist is a source of objectivity, which the patient can use to work through the transference distortions. In their relationship the therapist is maintaining a "mature" position for which the patient can aim. Loewald states, "In analysis, a mature object relationship is maintained with a given patient if the analyst relates to 
the patient in tune with the shifting levels of development manifested by the patient at different times, but always from the viewpoint of potential growth, that is, from the viewpoint of the future (1)."

As the distortions are stripped away the therapist becomes both more recognizable as a new object, and more available (from the patient's point of view). This continues to promote more intense work being done on deeper levels. Bar-Levav states, "Powerful confrontations must occur during the process of therapy between the patient's health and illness, between thoughtfulness and feelings, between rationality and irrationality, between mature living and infantile tendencies. All these inner struggles are expressed between patient and therapist (12)." The real-relationship develops strength as the therapist supports the patient's selfsufficiency and does not tolerate actions based on irrational feelings. As deeper levels of illness are exposed, and deeper levels of health attained, patients are better able to discern and use the real-relationship to address reality and combat their distortions.

Loewald speaks eloquently of how the therapist appropriately helps the patient develop into the person they can be. He states, "Through all the transference distortions the patient reveals rudiments of the core (of himself and objects) which has been distorted (1)." He believes it is the therapist's responsibility to the patient to fully comprehend and realize that core. The therapist must always keep it in sight as the patient attempts change. "If the analyst keeps his central focus on this emerging core he avoids molding the patient in the analyst's own image or imposing on the patient his own concept of what the patient should become (1)." It requires objectivity and neutrality on the part of the therapist, with respect for the individual and their unique development. Such will guide the patient in his or her renewed development in a reality based manner while proceeding through the developmental process unfolding in the therapy.

There is, then, some precedent upon which the therapist can base his or her interventions with the patient. It requires much skill and thoughtfulness on the part of the therapist to look beyond the adult body and adult words that are being spoken. These adult images are also a facade covering more essential aspects of the human being that we need to see clearly. Bar-Levav has described this as the necessity of recognizing the infant present in every patient who sits before us as an adult (12).

The responsibility for mediating in this process falls heavily on the therapist's shoulders. It is not to remake the patient in an image preconceived in the therapist's mind; the therapist has to maintain a clear view of the patient and must work intensely on themselves to prohibit their biases from intervening. This of course pertains to the therapist's countertransferential or theoretical biases. A therapist must continually evaluate his or her position and understanding of each patient. A commitment should be made on the therapist's part to participate in regular supervision with peers committed to the same process so that such issues can be worked with most effectively. This requires that the therapist face a similar, not identical, process as the patient, with his or her peers. He or she must critically regard his or her situation with the patient and clarify any confounding distortions. The therapist must then make the difficult shift inside and "change" also. And this 
must be done with the patient's interests in the forefront. Of course, implicit in these statements is the belief that therapists should have their own course of treatment, before attempting this work with patients.

In conclusion, if we thoughtfully consider what is available to us to help patients change their lives, the real-relationship can be a powerful force in the work. It will assist both the patient and therapist in immeasurable ways throughout the process. Our patients' pathology can place great limitations on their ability to live in reality, especially when strong feelings are present. It is our responsibility to help them find out that they don't have to live with the fear, loneliness, and pain which their distorted experience has led them to believe is the only truth. Rather we must help them see that they can live more simply and respectfully, in a real world peopled by real people, if they can make a more conscious choice.

\section{REFERENCES}

1. Simons, R: Our analytic heritage. Presidential address, Fall meeting of the American Psychoanalytic Association 1988

2. Loewald, H: On the therapeutic action of psychoanalysis. Int. J. Psycho-Anal 1960; 41:16-33

3. Greenson, R: The working alliance and the transference neurosis. Psychoanalytic Quarterly $1965 ; 34: 231-249$

4. Lipton, SD: The advantages of Freud's technique as shown in his analysis of the rat man. Int. J. Psycho-Anal 1977; 58:255-272

5. Sterba, R: The fate of the ego in analytic therapy. Int. J. Psycho-Anal 1934; 25:117-126

6. Viederman, M: The influence of the person of the analyst on structural change: a case report. Psychoanalytic Quarterly 1976; 45:231-249

7. Greenson, R: The Technique and Practice of Psychoanalysis, New York, Int. Univ. Press, 1968

8. Viederman, M: The real person of the analyst and his role in the process of psychoanalytic cure. J of the Amer Psychoan Assn 1991; 39(2):451-489

9. HarPaz, N: Beyond Character Analysis. Conference; Beyond Character Analysis: Focusing on the Healing Forces in Psychotherapy 1992

10. Greenson, R: Explorations in Psychoanalysis, New York, Int. Univ. Press, 1978

11. Menaker, E: The masochistic factor in the psychoanalytic situation. Psychoanalytic Quarterly 1942; 11:171-186

12. Bar-Levav, R: Thinking in the Shadow of Feelings, New York, Simon and Schuster, 1988

13. Blum, H: Psychic change: the analytic relationship(s) and agents of change. Int J Psycho-Anal 1992; 73:255-265 